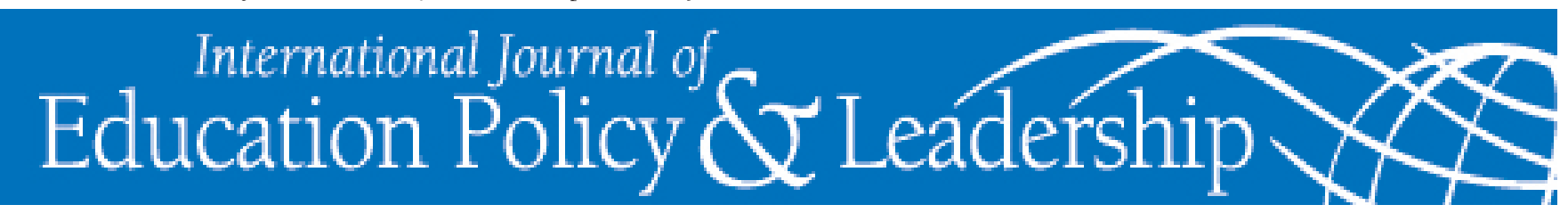

\title{
Principal Leadership in New Teacher Induction: Becoming Agents of CHANGE
}

\author{
FINNEY CHERIAN \\ University of Windsor \\ YveTte DANIEL \\ University of Windsor
}

\begin{abstract}
This small-scale pilot study investigated the role of school principals in the induction of new teachers in Ontario, Canada. Building upon the theoretical framework of Bolman and Deal (2002), as well as interviews, document analysis, and review of extant literature, the following findings were established: (a) Principals expressed that the educative mentorship of novices requires the engagement of the entire school community; and (b) Principals, veterans, and novices saw teaching as an intellectual, moral, and political endeavor that required their collective involvement. We suggest that principals employ the notion of "communities of practice" to instill a culture of support for new teacher induction.
\end{abstract}

Cherian, F. \& Daniel, Y. (2008). Principal leadership in new teacher induction: Becoming agents of change. International Journal of Education Policy and Leadership 3(2). Retrieved [DATE] from http://www.ijepl.org.

After about two weeks into the school year, I began to dread getting out of bed in the morning. I could not imagine how my day would unfold or how I was going to survive it. I only hoped I could make it through the day without my principal walking by to witness the utter pandemonium that was my classroom. Yet, I dared not break down and cry. I was afraid that word would travel quickly to the principal. I had to put up a façade that things were going well.

-From the journal entry of one novice teacher

The need for teacher induction programs has been triggered by the high attrition rate among novice ${ }^{1}$ teachers. Although the numbers might vary in different contexts, 20-30 percent leave the field within the first three years, and after about five years, an estimated 50 percent of beginning teachers have left the profession entirely (Angelle, 2002); Birkeland \& Johnson, 2002; Brewster \& Railsback, 2001; Colley, 2002; DePaul, 2000; Hope, 1999; Wong, 2002). Often, teachers point to lack of support from the school principal as a key reason for leaving (Roberston, Hancock, \& Anderson, 2006). In the open- ing quote, which comes from the journal of a novice teacher, the writer reflects that keeping her distress and apparent lack of confidence from the principal was her major concern. At the same time, it is important to note that principals also face unprecedented pressures related to school improvement and rely on the professional expertise of their teachers to achieve this goal.

In recent years, however, most professional educators have begun to realize that unrealistic expectations placed on novice educators can lead only to further attrition in the profession and a drain on already scarce resources. This enthusiasm for new teacher induction has not always been matched by clarity regarding the purposes and processes of educative induction practices. Induction is a socialization process (Angelle, 2002) through which novice educators have opportunities to rehearse and develop teaching skills under the mentorship of veteran teachers and school principals. This process helps them deepen their understanding of praxis (the reflective integration of theory, technique, and craft) and, more importantly, to develop a deeper sense of who they are as educators as they shape and are shaped by the mastery of the craft. 
In our small-scale pilot study, we investigated the perceptions of the role of school principals in the induction of new teachers in Ontario at a time when new teacher induction programs were being introduced across the province. Although the discourse centered on induction, many schools in the area in which we conducted our study did not have a formalized induction program at the time. Nonetheless, our study attempted to offer a conception of support that explored the possibilities of understanding the principal's key role in this process from multiple perspectives: school principals, veteran teachers, and novice teachers.

We have organized our discussion of this topic into five main sections. First, we discuss the main themes emerging from extant literature on induction, such as the complexities of career entry, the principal's principle role, and the novice's role in induction. Next, we provide the theoretical framework for our research. The third section is an overview of our study, followed by a section on research findings that bring to the forefront the lived reality of induction. Finally, we discuss some key considerations in planning for principal support for new teacher induction.

\section{Themes from Extant Literature}

\section{Balancing Survival and Discovery}

We focus on the first two stages of the five stage professional life cycle of teachers as indicated by Dolmage (1996). The five stages are: (1) career entry, (2) stabilization, (3) diversification and change, (4) resolution and non-resolution, and (5) disengagement and retirement. The first stage in the professional life cycle of teachers, the career entry stage, is marked by two main themesdiscovery and survival. Discovery relates to the sharp learning curve that teachers face in their first years in the profession (Dolmage, 1996). The other theme, survival, is dominant at this stage. Teaching is a complex activity fraught with tensions. Thus, the survival theme is associated with the multifaceted, messy, and unpredictable reality of classroom practice that appears to be far removed from the professional ideals espoused during the learning-to-teach phase. In the second stage, stabilization, teachers develop a sense of instructional mastery, a sense of self-efficacy, and personal commitment.

The raison d'etre for a teacher induction program, therefore, is to assist teachers in moving from the "baptism by fire," or entry stage, into the second stage, stabilization, aiming to, as Cohen (2005) states, "soften the stark contrast between the demands and working conditions of teaching and the neophytes' preconceptions and motivations surrounding teaching" (p. 1). Thus, the induction experience is a process that consists of a series of well-planned events provided in a supportive environment as teachers learn to practice their craft. The principal, as the instructional leader and facilitator of these experiences, has a pivotal role in the process.

\section{The School Principal's Principle Role in the Induction Process}

Decisions and actions by principals that promote the ultimate goal of enhancing organizational learning are integral to successful induction. The principal is a critical agent in the lives of novices and mentors them in a variety of ways, sometimes directly and sometimes indirectly, through the culture established in the school. The principal guides novices to regard teaching not only as grounded in curriculum and technical expertise but also as an engagement in inquiry, critique, caring, and social justice. Further, the principal plays an important role in developing an authentic sense of caring among teachers, who are, to the same extent motivated and expected to provide professional care for their students (Jazzar \& Algozzine, 2006).

The important role that principals play in the induction of new teachers is further underscored by the fact that new teachers are more influenced by the context and support in their initial school settings than by teacher preparation programs. Many teacher candidates and novice educators tend to valorize on the job training as the most important element in their training (Britzman, 1991). Working conditions that include time, observation, subject matter and schedule (TOSS) (Angelle, 2002) that principals can influence to a great extent, do make a difference. One of the most frequent reasons teachers give for leaving the profession is the poor quality of support from the school principal (Richards, 2004). To create a positive culture that affects teacher retention and helps teachers not only survive their first years but also thrive in them, successful school leaders must use effective strategies to address at least some aspects of their organization, such as structures, purpose, politics, and symbolic awareness. Principal leadership is a key component in creating a collaborative learning environment that contributes not only to the retention of new teachers but also to nurturing teachers who can meet the expectations of working in a complex milieu of diversity and change (Feiman-Nemser, 2001; 
Wayne, 2005).

Wood (2005) emphasizes that principals have five key leadership roles in induction: (1) culture builder, (2) instructional leader, (3) facilitator of mentors, (4) recruiter of new teachers, and (5) advocate for new teachers. Principals, as instructional leaders, are responsible for ensuring that a culture of induction and support is embedded within their schools. It is their responsibility to ferret out the structure and politics of the school culture that present impediments to the successful induction of new teachers. In general, three keys points have emerged with regards to the principal's role: working conditions for new teachers, time and resources, and a new role in induction

Working conditions. Most schools still operate from "veteran-oriented" cultures (Johnson \& Kardos, 2002). Principals must guard against the practice of assigning beginning teachers the leftover assignments, usually the more difficult groups of students or subjects that veterans reject (Hope, 1999; Jorissen, 2002; Stanbury, 2001). The Ontario College of Teachers' Transition to Teaching survey reported that many new teachers end up getting the worst teaching assignments, such as mixed-grade classes, Education Quality and Accountability Office (EQAO) test years, and placements in portable classrooms. They wanted extra support, but only 23 percent of those who found teaching jobs in 2003-04 reported receiving any formal induction or mentoring (Ministry of Education, Oct 4, 2005). It is the principal's responsibility to negotiate these assignment issues with veteran staff and to convince them that, in terms of equity, new teachers must be given certain advantages to ease their transition into full-time work. In general, principals are instrumental in ensuring a shift from a veteran-oriented professional culture to a noviceoriented professional culture (Johnson \& Kardos, 2002). For example, a prominent issue that emerged in relation to working conditions is the scarcity of resources for new teachers. Thus, a new teacher is left to scramble for resources such as instructional materials, textbooks, novel-study book sets or even basic items such as staplers or pencil sharpeners. The principal ought to consider the benefits of establishing processes for ensuring that resources are ready and available for the new teacher.

Principals need to encourage teachers who have demonstrated effective classroom programs to guide new teachers in managing the day-to-day complexities of work and assimilating into the culture of the profession and school as productive innovators and practitioners of the teaching craft. Even when support is not available at the same school, a buddy or mentor should be assigned from another school to arrange for collegial and supportive activities. Principals can outline what are considered reasonable expectations of a mentoring program (Ganser, 2002).

Furthermore, principals must finesse the schedule so that new teachers and their mentors have the same preparation times. In this task, principals must consider issues related to the collective agreements of teachers' federations. They need to be knowledgeable about the constraints and possibilities inherent in teachers' collective agreements.

A new role. In a milieu of unprecedented pressures for change and improvement in schools, the role of the principal changes from direct support to indirect facilitation of support. For example, the principal ensures that structures are in place for the beginning teacher to receive substantial and meaningful support at the school. Further, planning a successful induction program at the school level requires frequent and worthwhile interactions between the principal, mentor teachers, and new teachers who are anxious to meet the principal's expectations (Angelle, 2002). Therefore, expectations should be clarified through meetings, observations, and ongoing communications. The state of Connecticut has a comprehensive induction program called Beginning Educator Support and Training (BEST) (Youngs, 2002). This is a two to three year induction program for beginning teachers in which school and district based support teams provide a well-planned program of support and assessment. The support focuses on curriculum, instruction and assessment. Beginning teachers prepare a comprehensive portfolio that documents their learning and growth. Youngs' (2002) report on two districts using BEST highlights the significance of the principal's role. The following passage from his report emphasizes this point:

Further, Hartson had meaningful conversations with his principal, Dwight Bellamy, about instructional issues. Bellamy devoted copious amounts of time to writing up classroom observations, and discussing them with his teachers. While he followed the district's evaluation instrument, modeled after the Connecticut Competency Instrument (CCI), he was knowledgeable about the new state teaching standards and portfolio requirements. (p. 31) 
Similarly, Ontario has recently introduced the Teacher Performance Appraisal process, whereby principals evaluate teacher performance twice in the first year of teaching. Principals have to become knowledgeable not only in implementing the process but also in understanding the ways in which it supports the induction experience. Next, we discuss the role of the novice-also an important factor in this equation.

\section{The Novice's Role in Induction: The Readiness Factor}

In addition to the issues discussed above, we must also analyze the role that new teachers have in their own induction. It is easy to assign more power and influence to induction in its various forms than is warranted. The ideal induction program will remain just that-an ideal—due to lack of clear policies, time allocation, lack of resources, and other limitations. Further, it is important to recognize the knowledge, skills, attitudes, and assumptions that new teachers bring. Most teachers develop a conceptual framework about teaching and learning based on their childhood experiences, and teacher education does not have a significant impact on these assumptions (Robertson, 2006). In addition, if a new teacher "is weak in some essential skills, it is probably unreasonable and unfair to expect mentoring to eliminate the deficiency" (Ganser, 2002, p. 9). This assertion was evident in our interviews with veteran teachers and principals, who concurred with the above claim to argue that even the best induction program could not be successful unless the novice had something substantive to offer and was willing to change assumptions and attitudes. Hence, assessing teacher readiness is an important factor in successful induction. For example, the Connecticut Competency Instrument (CCI) measures teachers' general teaching competencies through a series of observations and interviews at the start of their teaching assignments (Youngs, 2002). This establishes a baseline from which induction activities are tailored to meet individual needs.

\section{Conceptual Framework of the Study}

A review of the extant literature indicates that the principal has a key role in the induction experience. The four aspects of the organization that determine the culture and climate of schools-structures, politics, human resources, and symbolic awareness-are derived from the concept of frames articulated by Bolman and Deal (1997, 2002). Since induction "is as much about schools and school culture as it is about supporting individual teachers" (Olebe, 2005, p. 159), frame analysis allows principals to move beyond static understandings of the structure and function of induction in their organization. These frames assist school principals in understanding that multiple perspectives must be employed to understand the complex and nonlinear organization of schools; thus, the principal's role in the induction of new teachers should also be viewed through multiple lenses. Even more compelling to note is the interdependence and the interrelationships between frames: "like a mobile, it is hard to touch one frame without setting off a reaction in all the others" (Louis, Toole, $\&$ Hargreaves, 1999, p. 259). We use frame analysis to study the roles and responsibilities of principals in supporting beginning teachers.

The structural frame is based upon a rational approach that holds people accountable not only for the responsibilities they undertake in a formal structure but also in more informal ways. The principal is called upon to coordinate the efforts of individuals and groups within the organization. The central question when using the structural frame is: How could we organize schools to support the induction of new teachers using a multifaceted approach that takes into the account the complex process of teacher induction? School structures are in a state of constant flux and adaptation (Morrison, 2002). As new teachers enter the profession, principals must consider the ways in which the structures of schools mandate that changes happen-not in isolation, but within a complex and fragile web of relationships.

Whereas the structural frame underscores the importance of a rational approach, the political frame "points out the limits of authority and the inevitability that resources are almost always too scarce to fulfill all demands" (Bolman \& Deal, 2002, p. 3). The political frame considers the manner in which the school, under the stewardship of the principal, creates the internal and the external support to change current practices to support new teachers. Louis, Toole, and Hargreaves (1999) argue that "the language of educational change is full of political terms; agenda setting, stakeholders, coalitions, political will, arenas, conflict resolution, resource allocation, political pressures, and constituencies" (p. 262). As principals take on the role of critical agents in new teacher induction, they have to contend with the political frames in skillful and innovative ways.

The human resources frame examines the role of people collectively within the organization as they learn to 
change practices, solve problems, and support their new colleagues through effective problem-solving strategies that include sustained interaction and mutual support. This frame underscores the significance of individual needs and motives within a social system. The principal has to employ strategies of shared decision making, provide opportunities for participation, and work towards enlisting commitment to new teacher induction.

The symbolic frame is also referred to as the cultural perspective for viewing organizations. Each school has its own distinct culture, also known as "the way we do things around here." Bolman and Deal (2002) posit that "symbols govern behavior through shared values, informal agreements, and implicit understandings" (p. 4). Therefore, the central question focuses on the culture of the school and its role in the induction of new teachers. How do principals, veteran teachers, and beginning teachers use their understandings of the cultural and symbolic perspective to support induction? Individuals use different schemata to interpret their experiences; hence, meaning is not always shared. This frame suggests that the principal plays an important role through direct contact and other means of creating a professional learning culture supportive of new teachers. Every principal, therefore, has to adapt generic implementation policies for induction to the needs of his or her school's organizational structures and climate.

As stated earlier, Louis and colleagues (1999) likened these frames to a mobile, where touching one frame sets off the others. Therefore, as we employ these frames in exploring the important roles that school principals play in teacher induction, we are cognizant of the complexity and the interconnectivity of these frames in the lived reality of schools. If we are serious about supporting new teachers, then we must consider the larger contexts in which this induction takes place to ensure a sustainable process. Our study, described briefly below, is an attempt to understand the complex role of the principal in the induction experiences of novice teachers.

\section{The Study}

Our pilot study was a tentative exploration of the key expectations that new teachers have of school principals as they try to make sense of these professional realities. It also explored principals' understandings of the structural and operational elements of new teacher induction and retention. We analyzed policies and practices by which school principals contributed to new teacher induction and retention.

\section{Research Questions}

Two major questions guided our study. First we wanted to find out what new possibilities existed for administrators in teacher induction programs. Next, we wanted to investigate how the roles of principals support the unique needs of novice educators. When we first forwarded this proposal, we had hoped that the induction process would be formalized in the 2005-06 school year (Ontario Ministry of Education, 2005). However, when we collected our data in fall and winter 2005-06, the Ministry had yet to formalize induction as outlined in the New Teacher Induction Program (Ontario Ministry of Education, 2006 Hence, we could not gather data on the recent NTIP initiative. We plan to expand our investigation in the coming years to examine the efficacy of NTIP in Ontario.

\section{Research Context}

Our study took place in a mid-sized city in southwestern Ontario in collaboration with one of the local school districts. The student enrollment number for September 2004 was 18,250 students in 41 elementary schools and 10 secondary schools. Next, we approached the principals of nine individual schools via phone calls and emails. We ensured that there was a balance between inner-city and county schools and elementary and secondary schools on this selected list. Three schools consented to participate. ${ }^{2}$ Two were secondary schools (one county and one inner-city) and one was an elementary inner-city school. At the initial meeting, we asked principals to identify teachers who were in their first five years of teaching and veteran teachers who served as mentors to these new teachers. We sent letters to participants explaining the project and the extent of their involvement and guaranteed all participants confidentiality. New teachers, especially, were reassured that anything that was said in the interviews would remain confidential and that they would not be identified in the report or in subsequent publications. In all, we had 22 participants: 3 principals, 1 department head, 13 novice teachers, and 5 veteran teachers serving as mentors.

\section{Interviews and Documents}

Our primary method of collecting data was interviews. Patton (2002) noted that the interviewer's skills largely determine the quality of information obtained. Therefore, we carefully considered interview questions using a semi-standardized interview (Berg, 2004) format in which deviations are allowed in order to adapt to the 
context and to gather as much information as possible. An interview protocol guided by the main questions was created to ensure consistency across the three schools. In designing the questions we were cognizant of the four specific types of questions that could be included during the interview: essential questions, follow-up questions, throw-away questions to establish rapport and to gather demographic data, and probing questions (Berg, 2004). Questions were open-ended to some degree to allow for interviewees to expand on their perspectives as they related to the quality of the orientation, induction, and socialization experience and the school principal's key role in this process.

In our interviews, we examined the level of assistance from the school in general and the level of administrative support and monitoring received by beginning teachers. We also noted the induction system at each school. Interviews were conducted with the principals, new teachers (less than five years of teaching experience), and veteran teachers who served as mentors. Principal interviews provided insights into the moral or ethical and instructional elements of their leadership when making decisions about the induction of new teachers at their school. Beginning teachers were provided opportunities to reflect upon their induction and to describe the role that the principal played in the process. Veteran teachers, who served as informal mentors, were interviewed to develop a better perspective on how they viewed their role and how they were supported by their principal in taking on this responsibility.

Another source of data collection included various documents related to policies and programs on teacher induction published at the Ministry and school board levels. These were useful sources of information that guided us in framing interview questions and conducting our analysis.

\section{Data Collection and Analysis}

Data collection and analysis occurred concurrently during our regular team meetings, where we compared notes and developed possible codes to categorize data. We analyzed the interviews conducted with novice teachers, veteran teachers, and school principals, then transcribed the interviews and sent each interview to participants for feedback and clarification. We coded the transcripts and then analyzed them specifically in relation to the objectives and questions noted above and more generally in keeping with the conceptual framework of the study. Obviously, this small sample is not rigorous enough to allow for broad generalizations, and transferability is a concern in a qualitative study of this dimension. However, our exploratory pilot project provides insights into some of the pervasive issues related to the induction of new teachers and, further, lays the groundwork for a comprehensive and broader project to track the induction initiative in Ontario.

We have abstained from making the claim of triangulating data because in a qualitative study of this nature, notions of validity and reliability have to be conceptualized differently than in a traditional quantitative study. Richardson (2000), as paraphrased in Goodnough (2001), argues against the notion of triangulation of data, claiming that "this assumes that there is a fixed point or object that can be triangulated" (p. 223). Rather, in our complex world of postmodern notions of fluidity and change, the notion of "crystallization" is more appropriate in asserting that what one learns through qualitative interpretation depends on the researcher or observer's holding and viewing of the crystal or lens. Therefore, we acknowledge that our perspectives and understandings have shaped this project.

\section{Limitations}

Two limitations are evident. Our research was conducted in a selected area in southwestern Ontario and the respondents selected for interviews were based on purposeful sampling. Also, our study did not include teachers who had left the profession within the first few years or retired teachers and principals.

\section{The Lived Reality: Voices from the Field}

In previous sections, we discussed some of the common themes related to the important role of principals in the induction of new teachers. Although induction for new teachers is highly sought after in concept and practice, the process should account for the complexity of the four frames within which induction takes place at the school level in which the principal plays a pivotal role.

\section{Collective Responsibility for Induction}

The principal is the social architect whose leadership style is developed with a focus on structure, strategy, environment, implementation, experimentation, and adaptation, as indicated by the frame metaphor of Bolman and Deal (2002). Successful induction is a collective responsibility. The principal plays a vital role in creating a structure supportive of the induction process (Wood, 2005). As one high school principal we interviewed claimed: 
I am really excited about the possibility of an induction program. One of our teachers initiated a conversation with the union president with regards to the letter of intent that is in our collective agreement. Because we are very much about being a professional learning community. (Principal, School \#1)

This principal recognizes the tensions between the teacher unions or federations and the school board. Structures of induction that would foster a learning community are contingent on collective agreements of the various bargaining units of the teachers' federations. School principals operate under many structural constraints. In this case, principals, although aware of the pressing need for support for new teachers, were instructed to wait until they received directions from the school board.

A new (third-year) teacher commented on his understanding of the principal's role in the induction process:

I don't see the attrition among new teachers as a direct correlation with the support from the principal. It might be other staff, right, because they're the ones you are working with on a daily basis, just because of practicality and the location of where the principal is in relation to the rest of the school. (Teacher, School \#1)

The above quote from one participant highlighted the importance of the political and the human resources frames. To this teacher, the principal seemed remote and not someone he would necessarily approach for assistance. However, as a school leader, the principal facilitated the tone and direction of the organization. Under the stewardship of the principal, individual needs and motives ought to be balanced with the needs of the collective. Did the established culture of the school support new teachers in their induction, or was it the sink-orswim attitude and a need to incorporate an understanding of "the way things are done" at the school? How could the principal become instrumental in changing "the way things are done" so that the way to support new teachers was embedded in the culture of the school?

In addition, the principal was called on to manage the political issues that affected power relationships and status. For example, we raised the issue of new teachers' getting the "leftover" assignments or having to face classrooms stripped of resources. Veteran teachers often feel that they have earned better assignments after years of being given the difficult ones, and further, they feel that resources accumulated over the years become personal property. In many cases, these issues have become one of those unwritten, but taken-for-granted, norms of the organization. One novice teacher (first year in a large high school) said:

When I came in, I didn't even have a desk where I could put my things, so I was carrying everything around with me during the day. I didn't know where to get textbooks and other materials. This high school is huge, and you can go around for months, and very few people would know who you are. For a new teacher, the only way I can get a better assignment is if a teacher goes on maternity or some other kind of leave, and for four or five months. So, that way you get a respite-some good classes and not all at the applied level. (Teacher, School \#2)

This is one new teacher's perception. However, the principal at the same school was aware of this problem from his own experiences as a beginner and said:

I thought, "What a terrible way to introduce a new staff member," using, like, a pecking order when it comes to seniority and supplies. We want to make sure they have everything they need with supplies and equipment and that they don't get the leftover courses - that we have them in the right courses, rather than the leftover. (Principal, School \#2)

Another novice teacher at an elementary school reported:

Yes, that's the other thing. You arrive, and in most cases, you get the assignment right before the Labor Day long weekend. You arrive to an empty classroom. So, here you're trying to prepare for the first day. You have to scramble for resources on top of everything else. (Teacher, School \#3)

This teacher's perception was corroborated by another principal who recognized the importance of trying to provide new teachers with appropriate schedules but noted that when teachers were hired at the end of the summer, this became increasingly difficult to plan.

\section{Teacher Readiness and Initiative}

We do not wish to give the impression that all new teachers we interviewed faced such situations. Even within the same school, we had differing perspectives on the same topics. One teacher felt that people would assist her and that the new teacher should take the initiative (new teacher readiness). In most cases, other teachers would offer to share their resources and lesson plans. The limi- 
tations of time served as the biggest impediment. As one teacher commented:

Everyone is so busy. I can go to other teachers, but I don't want to bother them all the time. So, first, I'll try to see if I can do it on my own. But, then, I'm a very independent person. I want to try things out on my own. (Teacher, School \#3)

\section{Principal as Instructional Leader}

Time was also a precious commodity for principals who were asked to take on different leadership roles in addition to their managerial tasks. The notion of instructional leadership was important to all the three principals we interviewed. Ideally, they understood the importance of their role as instructional leaders for all teachers, and especially for new teachers. The demands of the job, however, posed major obstacles:

And one of our biggest challenges right now, and to effect change, and to transform teaching and learning for diversity, and to do this work with teachers is time. The paperwork and the computer reports are taking us away for our work of becoming truly effective instructional leaders. We are doing more and more clerical work. But the biggest issue is time. There isn't time built into the day to work with people on a more diligent basis. (Principal, School \#2)

These sentiments were echoed by all three principals in different ways. They did not articulate how instructional leadership would be conceptualized and implemented at their school. When one veteran teacher was asked about instructional leadership, she claimed that more experienced teachers were in a better position to take on that role than were school principals:

That's a good question. I think, maybe, a teacher-because he/she is better connected. An administrator could have been out for a while. And it doesn't take long to get out of touch. Not that you forget, but so many things have changed. New curriculum, new assessment techniques, and other such things. So, a teacher who is moving along with these changes would be better in this regard. (Teacher, School \#2)

One principal described her job as being reduced to dealing with people during the day and paperwork at night. All three administrators described feeling estranged from aspects of leadership that involved the development of new teachers. As one principal remarked:
I enjoyed the role of seeing myself as an instructional leader in school, but now most of my time is dealing with irate parents, union grievances, and making sure traffic in front of the schools flows smoothly at the beginning of the day and at dismissal. (Principal, School \#3)

Many principals felt that their educational leadership roles had been reduced to management of people, budgets, and behavior (teachers' and students').

\section{Implications for Practice}

Through the literature and our research, we recognized that when board of education members and policymakers speak of induction, they speak of reforms directed toward improving teacher instruction. Creating competent technicians of instruction and delivery of standardized curriculum were high on the agendas of many school officials. What is lost in this reform focus on teacher instruction is the emphasis placed on teacher learning.

\section{Using the Frames to Create Support for Induction}

To accomplish this, principals need to regard themselves as critical agents who draw upon the four aspects of the organization-structures, politics, human resources, and symbolic awareness-when they rethink school improvement policies and practices (Bolman \& Deal, 1997, 2002). These four elements provide a frame that allows principals to understand that multiple perspectives must be employed in understanding the complex and nonlinear organization of schooling.

Beginning teachers need explicit and ongoing support from their school principal to be successful. According to Colley (2002) and supported by our research findings, principals possess the ability to create an environment that will stimulate beginning teachers' full potential. Even when the mentoring process is fully implemented, teachers need additional advice and support from the principal. New teachers want to be acquainted with the principal's expectations regarding instructional practices, grading, and student achievement expectations. Beginning teachers describe supportive principals as those who are present in the daily life of the school as well as in the professional development of teachers. Some suggested that principals attend some of the same professional development activities as their beginning teachers to encourage dialogue and to provide support and continuity. Further, beginning teachers want their principals to visit their classrooms more often on an 
informal basis to provide instructional support, modeling of teaching and management strategies, and regular feedback. Beginning teachers described supportive principals as those who helped them set up professional goals, recommended relevant workshops, and worked toward building a professional culture of learning in the school community.

\section{Policy Decisions at the Local and Provincial Level}

Policymakers understand that the role of the principal in new teacher induction is complex, demanding, and multifaceted. Principals cannot do it alone; they need formal and ongoing quality support. Induction cannot be the sole responsibility of the principal. The community, school boards and other governing bodies, institutions of higher learning, and principals must work in concert to create a seamless and supportive induction process. This recommendation must be explored in the Ontario context, where Principal's Qualifications Programs are offered by various institutions. An internship component for new teachers could be incorporated with support from the institutions and the school boards. The issue of new teacher induction could become a mainstay of these course offerings so that it is embedded in the acculturation of prospective principals. Although the concept of instructional leadership has been underscored as a key factor in retaining new teachers, operational issues dominate most of a principal's school day. A task force could be assigned to look into this challenge and seek ways to make time for principals to engage in instructional leadership. In California, many induction programs include training for principals so that they can fully understand the process and support it (Wood, 2005).

A review of participants' comments indicates that their role as administrators in the NTIP is imbued with strong tensions between personal intentions, individual politics, and contradicting institutional objectives. While there is no debate on the relevance of mentoring new teachers, the entire culture of practice-schools, boards, and unions-needs to be committed to this enterprise.

\section{Creating Communities of Practice}

So what does a supportive community of practice that would allow new teacher induction mentorship to take deep roots in Ontario look like? Reflecting on the findings of this study, we suggest that understanding Wenger's (1999) conceptualization of "communities of practice" could pave the way to change the culture of schools to become more accepting of the personal and professional needs of new educators. Efforts in establishing such frameworks could place induction programs on a firm foundation of sustainability and beneficial outcomes.

Here we provide a brief overview of Wenger's (1999) "communities of practice," not as a panacea, but as a concept that holds possibilities for restructuring the four frames within which induction is experienced in schools. Wenger (1999) argues that learning (and, for our purpose, teacher learning) as a situated, social activity is mediated relationally in a "community of practice." The community of practice is ideally characterized by three dimensions: (1) mutual engagement, (2) a joint enterprise, and (3) a shared repertoire (p. 73). Such communities do not occur spontaneously; they are complex undertakings that require careful balancing of rights and responsibilities to maintain and sustain them over a period of time.

Mutual engagement is possible when participants are enabled within a community of practice that nurtures diversity in ideas, beliefs, practices, and competencies. In such a milieu there are bound to be tensions, discord, personal agendas, and gossip as part of the full, complex sphere of learning and working together. The principal and other school leaders embrace such a mutual engagement in creating a community of practice. The second dimension, joint enterprise, is the result of negotiation. The enterprise is joint because "it is communally negotiated" (p. 78). Over time, guided by school leaders (principals and others), "the joint pursuit of an enterprise creates resources for negotiating meaning" (p. 82) resulting in a shared repertoire, the third dimension of a community of practice. The shared repertoire is the discourse and the way of doing things that support novices as they make their way through the first years in the profession.

These "communities of practice" underscore the socio-cultural context within which learning takes place. Professional development arises out of the social context, so it is important to direct attention toward those practicing to become teachers whose identities are being renegotiated in the process of learning to teach under the leadership of administrators. Within such communities, novices are guided rather than abandoned in their development. 


\section{References}

Angelle, P. (2002). T.O.S.S. it to the new teacher: The principal's role in the induction process. Paper presented at the annual meeting of the International Mentoring Association, Fort Worth, TX.

Berg, B. (2004). Qualitative research methods for the social sciences (5th ed.). Boston: Pearson Education, Inc.

Birkeland, S., \& Johnson, S. (2002). What keeps new teachers in the swim? Journal of Staff Development, 23(4), 18-21.

Bolman, L., \& Deal, T. (1997). Reframing organizations: Artistry, choice and leadership. San Francisco: JosseyBass.

Bolman, L., \& Deal, T. (2002). Reframing the path to school leadership: A guide for teachers and principals. Thousand Oaks, CA: Corwin Press.

Brewster, C., \& Railsback, J. (2001, May) Supporting beginning teachers: How administrators, teachers, and policymakers can help new teachers succeed.

Northwest Regional Educational Laboratory (NWREL). Portland, OR: NWREL. Retrieved Oct 12, 2005 from

http://www.nwrel.org/request/may01/BeginningTeac hers.pdf

Britzman, D. (1991). Practice makes practice: A critical study of learning to teach. Albany: State University of New York Press.

Cohen, B. (2005, April). Organizational moderators of induction program effects. Paper presented at the annual conference of the American Educational Research Association, Montreal, Canada.

Colley, A. (2002). What principals do about new teacher attrition. Principal, 81(4), 22-24.

DePaul, A. (2000). Survival guide for new teachers: How new teachers can work effectively with veteran teachers, parents, principals, and teacher educators. U.S. Department of Education, Office of Educational Research and Improvement. Retrieved April 13, 2004 from http://www.ed.gov/teachers/become/about/survivalguide/title.html

Dolmage, W. R. (1996). So you want to be a teacher: The guide to teaching as a career choice in Canada. Toronto: Harcourt Brace.

Feiman-Nemser, S. (2001). From preparation to practice: Designing a continuum to strengthen and sustain practice. Teachers College Record, 103(6), 1013-1055.
Ganser, T. (2002, April 5). Supporting new teacher mentor programs: Strategies for principals. Paper presented at the annual meeting of the International Mentoring Association, Fort Worth, TX.

Goodnough, K. (2001). Enhancing professional knowledge: A case study of an elementary teacher. Canadian Journal of Education, 26(2), 218-236.

Hope, W. (1999). Principals' orientation and induction activities as factors in teacher retention. The Clearing House, 73(1), 54-56.

Jazzar, M., \& Algozzine, B. (2006). Critical issues in educational leadership. Toronto: Pearson.

Johnson, S., \& Kardos, S. (2002, March). Keeping new teachers in mind. Educational Leadership, 59(6), 12-16.

Jorrissen, K. (2002). 10 things principals can do to retain teachers. Principal Leadership, 3(1), 48-54.

Louis, K. S., Toole, J., \& Hargreaves, A. (1999). Rethinking school improvement. In J. Murphy \& K. S. Louis (Eds.), Handbook of research on educational administration (2nd ed., pp. 251-276). San Francisco: Jossey-Bass Publishers.

Morrison, K. (2002). School leadership and complexity theory. London \& New York: Routledge Falmer.

Olebe, M. (2005). Helping new teachers enter and stay in the profession. The Clearing House, 78(4), 158-163.

Ontario. Ministry of Education (Oct 4, 2005). Unique professional support for new teachers to help boost student performance. Retrieved Oct 10, 2005 from http://www.edu.gov.on.ca/eng/new/2005/0510.html

Ontario. Ministry of Education (2006). New teacher induction program: Manual for performance appraisal of new teachers. Retrieved April 5, 2006 from http://www.edu.gove.on.ca/eng/teacher/induction.html

Patton, M. (2002). Qualitative research and evaluation methods (3rd ed.). Thousand Oaks, CA: Sage.

Richards, J. (2004). What new teachers value most in principals. Principal, 83(3), 42-45.

Richardson, L. (2000). Writing: A method of inquiry. In N. K. Denzin \& Y. S. Lincoln (Eds.), Handbook of qualitative research (2nd ed., pp. 923-948). Thousand Oaks, CA: Sage Publications.

Robertson, M. (with Hancock, D., \& Allen, L.) (2006). Why novice teachers leave. Principal Leadership, 6(8), 33-36

Stanbury, K. (2001). What new teachers need. Leadership, 30(3), 18-21. 
Wayne, A. (2005). Improving teacher induction.

Educational Leadership, 62(8), 76-78.

Wenger, E. (1999). Communities of practice: Learning, meaning, and identity. New York: Cambridge University Press.

Wong, H. (2002). Play for keeps. Principal Leadership, 3(1), 55-59.

Wood, A. (2005). The importance of principals: Site administrators' roles in novice teacher induction. American Secondary Education, 33(2), 39-62.

Youngs, P. (2002). State and district policy related to mentoring and new teacher induction in Connecticut. New York: National Commission on Teaching and America's Future. (ERIC Document Reproduction Service No. ED472133)

\section{End Notes}

${ }^{1}$ New, beginning, and novice are used interchangeably. All these terms imply teachers who are fairly new (five years or fewer) to the teaching profession.

2 A number of the schools that we approached had newly appointed principals who did not feel that they were ready to participate in a research project in their first year in an administrative role. This is a recent phenomenon in our province. Due to large number of retirements over the past five to eight years, many of our schools have less experienced administrators. (The minimum requirement to register in a Principals Qualification Program is five years of teaching experience.)

IJEPL is a joint publication of the Association for Supervision and Curriculum Development, the Faculty of Education at Simon Fraser University, and the College of Education and Human Development at George Mason University. By virtue of their appearance in this open access journal, articles are free to use, with proper attribution, in educational and other non-commercial settings 90 days after initial publication. Copyright for articles published in IJEPL is retained by the authors. More information is available on the IJEPL Web site: http://www.ijepl.org 